\title{
SAÚDE E MEIO AMBIENTE NA PERIFERIA DA METRÓPOLE*
}

\section{Aurea Maria Zöllner lanni**}

RESUMO: A dinâmica ambiental urbana é um processo que pode ser visto a um só tempo como estruturante, pois cria e constrói paisagens, e desestruturante, pois as desarranja e altera. Também se recolocam as questões de saúde e cidade, não apenas aquelas relativas aos serviços, mas, inclusive, suas interações com o ambiente protegido. A pesquisa objetivou captar as percepções que os setores populares da Capela do Socorro têm sobre saúde e meio ambiente, através de entrevistas abertas com roteiro semi-estruturado. Os moradores da periferia da cidade produzem e reproduzem conhecimentos e práticas sociais próprias como recurso de preservação da vida, resultando na produção social do ambiente e da saúde. A condição de escassez faz com que os moradores criem estratégias próprias de conservação e preservação da vida, e o trabalho emerge como a ferramenta dessa produção social; "é a categoria trabalho que une ambiente e saúde para os setores populares da periferia da metrópole.

PALAVRAS-CHAVE: meio ambiente, saúde, periferia, setores populares, trabalho

* Este texto apresenta apenas parte da pesquisa realizada e que resultou na Dissertação de Mestrado defendida no Programa de Pós-graduação em Ciência Ambiental da Universidade de São Paulo em 1999.

** Pesquisadora Científica do Instituto de Saúde da Secretaria de Estado da Saúde de São Paulo 
A saúde e o meio ambiente são categorias sociais construídas no jogo das relações sociais, compreendendo sempre a natureza e a vida. No mundo moderno, estas questões estão colocadas em estreita relação com a questão da concentração das populações nas cidades. A intensa urbanização em curso no final deste século assume proporções inusitadas. No Terceiro Mundo, a América Latina é de longe a sua área mais urbanizada, pois vem sofrendo este processo há décadas devido não só à migração das populações das áreas rurais como também em razão das altas taxas de natalidade nas cidades (CAMPBELL, 1992).

As mudanças estruturais sofridas pelas cidades têm sido profundas e a urbanização, enquanto dinâmica ambiental, pode ser vista a um só tempo como estruturante e desestruturante. Desestruturante enquanto um processo que não planejado, espontâneo, pontual, intervém de modo a alterar, desarranjar, modificar. Estruturante enquanto processo que cria e redesenha paisagens, constrói novos lugares e ambientes.

Também se recolocam as questões da saúde e cidade, e que podem ser caracterizadas por dois aspectos principais, não excludentes entre si, que são: o acesso aos serviços públicos da saúde e a articulação de um novo conceito de saúde - enquanto qualidade de vida - que contemple outras dimensões da vida humana, inclusive suas interações com o ambiente protegido (RODRIGUES e col.,1992).

Neste contexto, a problemática saúde e meio ambiente revela-se particularmente importante para as populações das periferias das grandes metrópoles. Aí parecem precipitarse e condensar-se todos os aspectos do problema, bem como suas implicações práticas e teóricas.

Esta pesquisa objetivou captar a percepção, a compreensão que os setores populares da cidade de São Paulo, mais especificamente aqueles residentes na Capela do Socorro, região sul do município, têm sobre saúde e meio ambiente. Esses moradores articulam seus próprios conhecimentos como um recurso vital para a defesa de sua identidade, proteção de seus interesses e preservação de valores essenciais e da vida (Borda, 1981). Há em suas práticas cotidianas uma consciência que se expressa em ação. Aí, no universo do dia a dia, a arte de fazer é absolutamente idêntica à arte de pensar (CERTEAU, 1985). Pode-se considerar, então, que as práticas cotidianas expressam a construção social da realidade e por isso devem ser conhecidas, reconhecidas. Elas são ações e pensamentos.

Partindo-se destes pressupostos, a pesquisa concentrou-se na coleta de entrevistas abertas com roteiro semi-estruturado, junto a moradores da região. Os informantes falavam 
livremente sobre os temas propostos, delimitados por um roteiro de questões. O roteiro das entrevistas foi elaborado a fim de captar por meio da 'fala' dos moradores locais a construção social da saúde e do ambiente expressa em estratégias próprias de sobrevivência e conservação - técnica válida para compreender os valores culturais e as representações de determinado grupo sobre temas específicos. Na medida em que a pesquisa propunha a apreensão de um saber produzido pelas práticas cotidianas, a 'fala' do morador era o grande recurso a ser explorado, pois ela permite recuperar a compreensão que se tem do percurso do dia a dia.

Foram entrevistadas dezoito pessoas, três homens e quinze mulheres, com idades que variavam de 15 a 86 anos, todas elas moradoras da região da Capela do Socorro. Não houve a preocupação com um critério de representatividade numérica dos indivíduos em relação a categorias tais como sexo, faixa etária, ocupação e nível sócio-econômico ou de escolaridade; não houve, também, a preocupação em definir o universo amostral dos entrevistados em relação ao total da população da região, pois não se pretendia a generalização dos resultados da pesquisa referidos a categorias sócio-demográficas. $O$ importante era captar o 'discurso' do morador e, a partir dele, captar as percepções sobre saúde e meio ambiente através de suas falas. Houve, portanto, o privilegiamento dos sujeitos sociais que detêm os atributos necessários - o conjunto de experiências - que se pretendia objetivar com a pesquisa (MINAYO, 1994).

A representatividade dos depoimentos foi considerada quando da recorrência dos temas abordados pelos entrevistados e pela articulação das várias entrevistas, o que possibilitou a composição do 'discurso' coletivo.

A análise do material teve início com a leitura atenta de cada um dos depoimentos, extraindo-se deles as questões e problemas referidos pelos informantes, consolidados nas seguintes categorias: terra, água, ar, lixo, saúde, doença e o cuidado, que foram trabalhados em dois grandes blocos temáticos - a produção social do ambiente e a produção social da saúde-doença. A sintetização dos depoimentos nessas temáticas centrais teve como perspectiva elaborar um 'discurso-síntese' dos vários discursos individuais. Trata-se de um 'discurso do sujeito coletivo' que represente a síntese de pensamento de um sujeito coletivo de natureza social (SIMIONI et al., 1997). Este 'discurso-síntese' pretendeu, pois, representar a percepção social daquele sujeito coletivo, o morador da Capela do Socorro.

\section{CAPELA DO SOCORRO, SÃO PAULO}

A região é uma dessas franjas periféricas urbanas. Ali, a ocupação é homogeneamente inacabada, improvisada. Uma extensão oceânica de autoconstruções 
inacabadas de blocos de cimento, que se espraiam pela topografia: morros, vales, córregos, represas. Paisagem entrecortada pelas poucas e precárias vias de acesso, as grandes veias distribuidoras de tudo o que circula na região.

Limita-se ao norte com o bairro de Santo Amaro e Campo Limpo, a leste com a represa Billings e o município de São Bernardo do Campo, a oeste com a represa Guarapiranga e os municípios de Itapecerica da Serra, Embú-Guaçu e Juquitiba e, ao sul na região da Serra do Mar -, com os municípios de Itanhaém e São Vicente.

Situada no extremo sul do município de São Paulo, Capela do Socorro tem uma superfície de $487,8 \mathrm{~km} 2$, representando quase que $1 / 3$ de toda a área geográfica do município de São Paulo e abriga uma população de 557.068 hab. (IBGE/SEADE, 1997). Localizada entre as sub-bacias hidrográficas da Billings, da Guarapiranga e dos rios Capivari e Monos, é uma das maiores áreas verdes do entorno de São Paulo, o que a torna uma região de importância metropolitana pois, além do papel no equilíbrio ambiental desempenhado pelos seus recursos ecológicos, seus mananciais contribuem com cerca de $30 \%$ da água que abastece a Grande São Paulo. Foi este fator que determinou a inclusão de quase $90 \%$ da região na lei de Proteção aos Mananciais, promulgada pelo governo estadual em $1975 \mathrm{e}$ que normatiza os usos do solo na região com a intenção de garantir a preservação desses recursos. Entretanto, essa legislação, devido ao seu caráter simplesmente restritivo, surtiu um efeito inverso ao pretendido. As grandes limitações impostas interferiram no mercado fundiário fazendo com que o preço da terra tivesse uma queda relativa (SILVA, 1991) tornandose, para as camadas pobres da população, um espaço disponível para moradia, já que estes setores não contam com alternativas no mercado privado legal ou nas políticas públicas de fomento à habitação popular. Será, portanto, nessas áreas de terras desvalorizadas e rejeitadas pelo setor imobiliário privado que a população pobre, trabalhadora, encontrará possibilidades de se instalar, encontrará possibilidades de construir sua moradia, seu habitat.

\section{A PRODUÇÃO SOCIAL DO AMBIENTE}

Os sistemas ambientais não se desenvolvem nem funcionam num vazio sóciocultural. Na tarefa de produzir e reproduzir a vida, os homens se apropriam de recursos não humanos, 'naturais', para a sua sobrevivência e conservação e, ao fazê-lo, desempenham uma função dinamizadora do meio ambiente. $O$ ambiente encontra-se, portanto, em permanente transformação, seja em virtude daquela ocorrida em suas forças e estruturas físicas, seja, também, em virtude da evolução de todas as formas de vida. O homem, inserido neste contexto, produz o meio que o envolve e é, ele mesmo, seu próprio produto (MOSCOVICl, s/ data). A natureza é, desta forma, parte da história da humanidade e suas 
transformações caminham par a par das transformações sociais. Não há, pois, natureza sem sociedade, e esta relação pode ser considerada uma relação em permanente equilíbrio dinâmico (DUBOS, 1968).

Ao produzir a si mesmo e ao meio ambiente o homem também se transforma. Pelo atributo da capacidade reflexiva, o homem usa e transforma os recursos da natureza de forma qualitativa e quantitativamente diferente dos outros seres vivos. Ele usa e transforma fontes de energia (solar, eólica, hidráulica, etc.) além, e diversamente, de qualquer outro ser vivo. O homem logrou, ainda, reproduzir outros seres vivos (FOLADORI, 1996). O atributo da reflexão é, neste sentido, atributo da produção social do ambiente. No tocante à ecologia humana, portanto, as percepções, representações e práticas sociais integram - intrínseca e deterministicamente - as condições de existência. Não é possível pensar o natural sem essa forma própria de vida que é a vida humana, social.

Esta dinâmica faz com que o homem desenvolva técnicas de usos e apropriação dos recursos da natureza a fim de satisfazer as necessidades vitais para a sua sobrevivência - alimentar-se, vestir-se, abrigar-se, etc.. Recurso é, por isso, "um conceito cultural. Recurso é o conhecimento de uma sociedade sobre o seu meio. É a capacidade de transformar em uma coisa útil um elemento do meio ambiente" (SACHS, 1985, p.34). Recurso implica, pois, a transformação da natureza pelo homem através de práticas sociais concretas, do trabalho.

"Eu não tinha água, não tinha luz. O vizinho meu lá da Chácara, que é o morador fundador dali do pedaço, ele me emprestou a água e luz, só que a água dele também era no poço. Aí tinha bomba pra eles lá, né, mas como a família também é grande, parece que é treze filhos, aí, eu pegava no balde, trazia no balde em casa (...)"

"Não tinha água nem luz. A água era dessa mulher que eu estou falando. A mangueira descia aqui, nós enchia os tambor de água aqui, um 'muntueiro' de tambor, deixava aícheio de água os tambor."

As técnicas de usos e apropriação dos recursos da natureza desenvolvidas pelos homens ao longo de suas vidas a fim de satisfazer suas necessidades vitais se revelam como práticas sociais cotidianas onde o saber é, quase que imediatamente, o fazer. E este 'saber fazer' não encontra expressão apenas no nível dos indivíduos, das famílias, mas se expressa também no nível das comunidades, das coletividades. A vida comunitária implica, freqüentemente, o aproveitamento dos talentos das pessoas e recursos disponiveis que a integram. A transformação dos elementos da natureza em recursos sócio-ambientais assume também uma forma coletiva de trabalho. 
"Então o asfalto, em casa, foi feito a mutirão. O pessoal juntava aqui, umas trinta pessoas e ia fazendo o asfalto, pondo assim aquelas vigas, aí depois lá com a ajuda da Prefeitura, ela veio, acabou de fazer o asfalto. Mas foi feito mesmo mais a mutirão. Por isso que eu digo que o bairro cresceu, porque quando eu mudei ali, a rua era um bequinho assim, um trilhozinho, todo cheio de mato assim (....)"

Não há problemas ambientais desvinculados de formações sociais, sejam elas simples ou complexas, de centro ou periferia do capitalismo. Os problemas ecológicos emergem tão somente de formas específicas de relacionamento dos homens com a natureza (GRUNDMANN, 1991/92), por isso são histórica e socialmente determinados e ecológicamente circunstanciados. E, em Capela do Socorro, cidade de São Paulo, os problemas ecológicos são problemas de metrópole e de periferia, de exclusão e de escassez.

"Além da questão dos lotes, tem as áreas que seriam áreas verdes, elas estão todas ocupadas por favela. Inclusive na beira do manancial todo, aquelas áreas que ficam preservadas na beira do manancial, elas foram invadidas por favela. $E$ isso, por um lado a grande necessidade da população, da moradia. E veio chocar exatamente com a proteção ao manancial, que é preservar as áreas verdes e preservar também a represa, e isso tem causado choque até agora. Porque toda área está povoada, e muitas das nossas reivindicações, a gente não consegue até hoje por conta disso, por conta da lei de proteção ao manancial, da importância que tem proteger o manancial e por outro lado a importância que tem a necessidade da população de morar, que as pessoas moram até debaixo da ponte. Então quando acham um local pra fazer um barraco, já é uma grande coisa e a gente vive aqui na região com este contraste."

"O ser humano, ele destrói as coisas, como eu falei, também por necessidade, por necessidade."

A produção social do ambiente na periferia da cidade é sobretudo a apropriação e potencialização dos recursos e talentos disponíveis. Recursos 'naturais', como o solo, a água, o ar, e recursos sociais potencializados através de práticas coletivas de produção de espaço e condições para moradia, de habitats. Trata-se de um trabalho produtivo especial, o de transformar o ambiente que se tem, no qual se vive.

\section{A PRODUÇÃO SOCIAL DA SAÚDE-DOENÇA}

As enfermidades são palpáveis, mais evidentemente percebidas do que a sensação de bem estar, de estar saudável, que é menos palpável, menos evidentemente percebida. 
O estado de bem estar, identificado como saudável, é qualquer coisa sobre a qual se tem, sobretudo, uma sensação e, apenas, uma idéia: organicamente, trata-se de um padrão ideal, que não se sabe muito bem no quê consiste e que, portanto, só é atingido mediante condições não apenas bio-físicas mas psico-sociais também. Saúde, assim compreendida, é um objetivo do qual se procura aproximar. Saúde é um estado, uma condição.

Esta falta de elementos e dificuldades em definir o estado de saúde faz com que seja impossível dissociá-la da doença. A única coisa que se pode afirmar é que saúdedoença representam graus opostos e relativos entre si de variações biológicas do organismo humano. Saúde-doença são a resultante do organismo humano em adaptar-se física, mental e socialmente às condições variáveis do ambiente de vida do homem. Saúde-doença é movimento, um processo de compensação, descompensação, adaptação, readaptação, desadaptação, compromissos que mudam, se perdem, se ganham, são reconquistados e redefinidos.

Para quem vive na Capela do Socorro, a saúde não é percebida como um estado ideal a ser alcançado. Para o morador, saúde é uma condição. Condição para viver bem, para trabalhar, para desempenhar funções sociais, para a reprodução da vida, condição de vida. "A saúde é, antes de tudo, uma sucessão de compromissos com a realidade" (DEJOURS, 1986, p.11). A saúde é estar bem, ter disposição, higiene, uma boa alimentação, sentir-se bem para trabalhar, viver com conforto, não depender dos outros para fazer as tarefas cotidianas, prevenir-se e prevenir aos outros de doenças. Por isso saúde é tudo. Uma condição para a reprodução da vida, de si mesmo e do meio ao seu redor.

"Uma boa saúde ? ... É você viver num lugar onde você se sente bem, começa daí."

Cada grupo social desenvolve um padrão distinto de relação com a natureza, o que vai conformar condições genéticas e fisiológicas típicas a partir dessa relação com o ambiente. Portanto, os processos da vida, nascimento, crescimento, adoecimento, morte, não são idênticos para todos os grupos, visto que as condições biológicas, bem como as sociais, também são diferenciadas para os diferentes grupos humanos em sua relação com o meio. Desta forma, o fenômeno da saúde no universo dos homens não é apenas um fenômeno biológico, mas um processo bio-social integrado, dinâmico. A saúde é percebida em sua determinação social, sofrendo transformações em conformidade com os fatores que the são condicionantes (VILAÇA MENDES, 1996), devendo-se levar em conta não apenas os fatores biológicos mas outros que também intervêm em sua determinação $e$ variação (sociedade, ecologia, ambiente, cultura, etc.).

"Na minha opinião, as condições de saúde da população é ruim na nossa região. É 
muito ruim porque dentro deste contraste que tem da falta de moradia, as invasões, os loteamentos que fizeram, tudo, na verdade, existe muito pouco saneamento básico, então eu acho que na nossa região, eu acho que Deus está com a mão em cima porque senão a situação seria muito pior. E quando você entra, por exemplo, numa favela aqui da região do Grajaú é que você vê o modo, o sistema que as pessoas vivem, e aí você chega até a pensar, ora, se Deus não pusesse a mão em cima desse povo, não sei o que seria desse povo, porque só por Deus que não acontece uma epidemia muito forte, na área tanto do Grajaú como toda área da Capela do Socorro. Então a questão de saúde do povo é muito ruim na nossa região."

"Saúde. O que é ? Saúde é higiene, é um pouco, né? Pode ser isso aí. É igualmente você ver uma cidade limpa; se ela estiver suja não está feia ? É que nem a pessoa também."

Não parece possível, portanto, definir saúde em termos absolutos e somente objetivos, muito menos pensar que saúde é a simples ausência de doença. Saúde e doença são fenômenos do processo da vida, e por isso um processo que varia sempre segundo os tempos, os ambientes e as circunstâncias ecológicas. Na medida em que estes conceitos são muito variáveis são, por isso mesmo, dinâmicos, históricos e se transformam de acordo com as épocas, mais exatamente com as condições de vida das populações e culturas de cada época.

"Saúde é a pessoa não sofrer nada de doença e ter força e vontade de trabalhar, que graças a Deus, desde nova eu fui uma guerreira pra trabalhar. (...)"

"Nunca estou doente, por causa que eu trabalho!"

Segundo LAURELL E NORIEGA (1987), na sociedade capitalista, por exemplo, o conceito de doença explícita está centrado na biologia individual, fato que lhe retira o caráter social. O conceito de doença oculta, quer dizer, que está subjacente na definição social do que é doença, refere-se à incapacidade de trabalhar. Não há dúvida de que o conceito de saúde-doença como condição para o trabalho está contido neste marco histórico que é o capitalismo. E é neste contexto histórico-social que vive o nosso morador.

"É muito importante a pessoa ter um trabalho, ter um conforto, viver bem com tudo. Porque a pessoa que está desempregada, não tem, chega em casa, as crianças querem comida, não tem, é aquele desespero, aí vai pro bar, vai bebermesmo que não tem dinheiro, né, e é aonde acontece só coisa ruim."

Para quem reside na Capela do Socorro, periferia da cidade de São Paulo, é assim. Assalariados - em sua grande maioria -, os moradores da região contam com a sua saúde 
como condição para a produção e reprodução da própria vida. A sua força de trabalho "é uma mercadoria muito especial. Com efeito, ela possui a propriedade particular de ser uma fonte que cria valor" (ENGELS apudMARX, 1975, p.14). Valor, este, inestimável para aquele morador que depende do único instrumento do qual dispõe para produzir suas condições de existência.

"Ficando doente você não vai poder trabalhar, não trabalhando você não recebe salário, não recebendo você vai começar a passar fome."

\section{CONCLUSÃO}

Ainda que na década de 80 não tenha havido no Brasil um aumento da dimensão da pobreza, houve, no entanto, o aumento das desigualdades sociais. Por isso, pensar a pobreza é pensar a partir da questão da desigualdade, das desigualdades sociais.

Capela do Socorro, periferia da cidade de São Paulo é um espaço, um lugar, onde moram as pessoas das classes populares. São, em sua maioria, assalariados das indústrias, dos serviços, subempregados, desempregados (estruturais, conjunturais). São, em sua maioria, gente pobre ou empobrecida, o quê quer dizer que é gente que não apenas não tem mas que está, sobretudo, "impedida de ter" (PEDRO DEMO apud MARICATO, 1996, p.57). A pobreza das populações da periferia da cidade pode ser definida, então, como a impossibilidade de ter, uma desigualdade social que marca as suas condições de vida. "A pobreza não pode ser entendida somente como fome, desnutrição, carência de renda, dentre outras carências, e sim como inadequação de recursos disponíveis para gerar capacidades individuais - cidadãs - minimamente aceitáveis, dizendo respeito, por conseguinte, à limitação dos modos de viver a que uma pessoa está condenada ...” (COHN, 1997, p.92).

Nas cidades, os 'homens comuns' das classes populares vivem no limiar da escassez de recursos, impedida de ter, uma desigualdade estrutural e estruturante. É esta desigualdade que qualifica as suas condições de vida. Há escassez de tudo: de moradia, de água, luz, transporte; escassez de salários, remuneração e serviços adequados; lazer, educação; escassez de espaço, de condições de vida. A vida, aí, se desenvolve no limite dos recursos. É esta escassez que qualifica aquela pobreza, é esta escassez que delineia o perfil dos moradores na Capela do Socorro. E esta desigualdade é imediatamente percebida pelo morador.

“Hoje em dia está um céu aqui, mulher, hoje em dia está um céu!" 
O morador sabe que tudo que se refira à esfera social envolverá escassez de recursos os mais diversos e a necessidade de produzi-los em condições de extrema dificuldade, de pobreza. A escassez - condição social - aparece, então, na percepção do morador, em contraposição à abundância - qualidade atribuída a tudo que pertença ao universo do 'natural'. A escassez é compreendida como uma qualidade da vida em sociedade, tendo no seu contraponto a natureza qualificada em abundância, fartura, fertilidade, fecundidade, produtividade.

"Meio ambiente faz parte da natureza, esse mato que a gente vê, essa coisa mais linda é o meio ambiente, eu acho. É a natureza, muita água, muito verde, muita flor, tudo isso, eu acho o meio ambiente maravilhoso! Porque esse lugar aonde a gente anda por aí, tudo cheio de fumaça, isso não é vida."

E porquê isto acontece? Porquê a vida em sociedade torna-se o reino da escassez? Os recursos da natureza e as capacidades humanas não parecem se caracterizar pela escassez e sim pela abundância. "Como se produz a metamorfose dessa abundância na escassez de recursos que registra a economia? Essa transformação é conseqüência da progressiva materialização das necessidades humanas e sobretudo da redução dos valores em valores de troca operada pela economia" (BOADA, 1991, p.14).

A predominância do valor de troca nos objetos e coisas da nossa sociedade penetra e se irradia por todas as esferas sociais e da relação homem-natureza. Isto faz com que tudo pareça se mover, na nossa sociedade, apenas pelo seu valor de troca, ou seja, o atributo de um objeto poder ser trocado, equiparado a outro. $O$ real valor dos objetos, das coisas, sua verdadeira função e utilidade fica obscurecida, subssumida pelo valor de troca, decorrente do predomínio dessa esfera nas relações sociais. Cria-se, então, uma idéia de 'abstração' em que tudo circula e se relaciona, na sociedade, pela sua capacidade de troca, apenas como coisa, e não pela sua utilidade, seu valor útil, intrínseco.

No que diz respeito à população pobre da periferia da cidade, a escassez impede essa inserção integral no mundo da troca, pois há uma exigüidade de bens e recursos a serem trocados. Ela tem que produzir seus próprios bens úteis. A superação dessa escassez requerá, sempre, estratégias de apropriação, produção e reprodução dos recursos, cotidianamente. Diante da impossibilidade de ter e sendo, entretanto, necessário ter para sobreviver, o morador que vive no espaço da cidade numa pobreza qualificada pela escassez produz e reproduz seus próprios bens e recursos para a vida. "Nos países do Sul, a observação das grandes cidades conduz a duas constatações: de uma parte, a emergência das estratégias de sobrevivência testemunham uma grande resiliência e engenhosidade das populações que vivem na 'cidade ilegal'; de outra parte, a escalada da violência 
provocada pela miséria, a revolta crescente diante da consumação ostentatória da minoria rica ..." (SACHS, 1996, p.3).

E o instrumento que torna possível ao morador transpor a fronteira dos valores - de uso e de troca - na vida cotidiana é o seu trabalho. Por meio do trabalho ele transforma os elementos, os objetos, em recursos; por meio do trabalho ele cria ambiente, habitat, cidade. O trabalho possibilita ter, ou seja, ter casa, ter água, ter saúde, etc., condição fundamental para a superação da condição de pobreza. $O$ trabalho lhe dá valor. $E$ a condição para o trabalho é a saúde que, como diz DEJOURS (1986), "é uma coisa de que se depende". Por isso ela é útil, tem seu valor.

O morador, na sua argúcia perceptiva - fruto do agir e do pensar -, manifesta claramente esta condição:

"Saúde é a gente ter saúde pra trabalhar. Saúde é isso. Saúde é tudo."

"A gente viver com saúde e pedir força e coragem a Deus pra gente trabalhar pra manter a casa, pra não faltar nada pros filhos da gente e pra gente, não é isso?”

O trabalho emerge, então, como um elemento estrutural da ecologia humana nas grandes cidades. É através dele que as populações sobrevivem, transformando recursos naturais em sociais. A saúde, por sua vez, emerge como o elemento propulsor da capacidade para o trabalho. O trabalho, portanto, unifica saúde e ambiente para os moradores da periferia da metrópole, Capela do Socorro. São Paulo.

\section{REFERÊNCIAS BIBLIOGRÁFICAS}

BOADA, L. O Espaço Recriado. São Paulo, Nobel, 1991.

BORDA, O.F. Aspectos Teóricos da Pesquisa Participante. In: BRANDÃO, Carlos R. (org.). Pesquisa Participante. São Paulo, Brasiliense, 1981.

CAMPBELL, T. Desenvolvimento Urbano no Terceiro Mundo: Dilemas Ambientais e Pobres Urbanos. In: LEONARD, H.J. (org.). Meio Ambiente e Pobreza: Estratégias de Desenvolvimento para uma Agenda Comum. Rio de Janeiro, Jorge Zahar, 1992.

CERTEAU, M. de Teoria e Método no Estudo das Práticas Cotidianas. In: SZMRECSANYI, Maria Irene de Q. F. (org.). Cotidiano, Cultura Popular e Planejamento Urbano. São Paulo, FAU-USP, 1985. 
COHN, A. Desenvolvimento Social e Impactos na Saúde. In: BARATA, R.B. (org.). Condições de Vida e Situação de Saúde. Rio de Janeiro, ABRASCO, 1985.

DEJOURS, C. Por um Novo Conceito de Saúde. Revista Brasileira de Saúde Ocupacional, 54(14):7-11, 1986.

DUBOS, R.J. O Homem e seu Meio Ambiente: Adaptações e Interações. In: A Humanização do Meio Ambiente. (Simpósio do Instituto Smithsoniano). São Paulo, Cultrix, 1968.

ENGELS, F. Introdução. In: MARX, K. Trabalho Assalariado e Capital - Salário, Preço e Lucro. Porto, Publicações Escorpião, 1975.

FOLADORI, G. Las fuerzas que guían el comportamiento humano con su ambiente. In: RAMIREZ, A.L. y HERNANDEZ, P.F. (coord.). Sociedad y Medio Ambiente: Contribuciones a la Sociologia Ambiental en América Latina. México, Associação Latinoamericana de Sociologia/Benemérita Universidad Autónoma de Puebla/ICSyH/ La Jornada Ediciones, 1996.

GRUNDMANN, R. El marxismo frente al desafio ecológico. Trabajo y Capital, Uruguai, 3:27-47, 1991/92.

LAURELL, A.C. \& NORIEGA, M. Trabajo y salud en Sicartsa. México, Programa de Difusión Cultural del SITUAM, 1987.

MARICATO, E. Metrópole na Periferia do Capitalismo: llegalidade, Desigualdade e Violência. São Paulo, Hucitec, 1996.

MINAYO, M.C.de S. O Desafio do Conhecimento: Pesquisa Qualitativa em Saúde. São Paulo, Rio de Janeiro, Hucitec - ABRASCO, 1994.

MOSCOVICI, S. Sociedade contra Natureza. Petrópolis, Editora Vozes, 1975.

RODRIGUES, R.H.; SABROZA, P.C.; LEAL, M.C. \& BUSS, P. A ética do desenvolvimento e as relações com a saúde e meio ambiente. In: RODRIGUES, R. H.; SABROZA, P. C.; LEAL, M. C. e BUSS, P. (orgs.). Saúde, Ambiente e Desenvolvimento. v. I. São PauloRio de Janeiro, Hucitec-ABRASCO, 1992.

SACHS, Y. Novas Necessidades do Planejamento nos Países Desenvolvidos. In: SZMRECSANYI, M.I.Q.F. (org.). Cotidiano, Cultura Popular e Planejamento Urbano. Anais do Encontro, São Paulo, FAU/USP, 1985. 
SACHS, Y. Introduction. In: Sachs, Y. (org.). Quelles Villes, pour quel Dévelopment? Paris, Presses Universitaires de France, 1996.

SILVA, L.O. da A organização do espaço construído e qualidade ambiental: o caso da cidade de São Paulo. Pólis. n. 3, 1991.

SIMIONI, A.M.C.; LEFÉBVRE, F. \& PEREIRA, I.M.T.B. Metodologia Qualitativa nas Pesquisas em Saúde Coletiva: Considerações Teóricas e Instrumentais. (mimeografado). USP/ Faculdade de Saúde Pública/Departamento de Prática de Saúde Pública. São Paulo, Série Monográfica n. 2., 1997.

VILAÇA MENDES, Eugênio. Uma Agenda para a Saúde. São Paulo, Hucitec, 1996.

\section{ENVIRONMENT AND HEALTH IN THE OUTSKIRTS OF THE METROPOLIS. SÃO PAULO}

SUMMARY: Urban environmental dynamics is a process that may be considered as both structuring, since it creates and builds landscapes, and distructuring, for it disorganizes and changes them. Health and urban issues are addressed, not only those related to services, but also their interactions with the protected environment. The research aimed at collecting Capela do Socorro community perceptions of health and environment by means of with a semi structured interviews. The city outskirts dwellers produce and reproduce their own knowledge and social practices as resources to preserve life, which results in the social production of environment and health. Shortage conditions make the dwellers create their own life conservation and preservation strategies. Work is the tool of this social production; it is the work category that links environment and health in communities of the metropolis outskirts.

KEY WORDS: environment, health, outskirts, communities, work 